\title{
Fetal Alcohol Spectrum Disorder: A disability in need of social work education, knowledge and practice
}

\author{
Dorothy Badry ${ }^{1}$ and Peter Choate ${ }^{2}$
}

\begin{abstract}
Fetal Alcohol Spectrum Disorder (FASD) is a non-diagnostic umbrella term that describes a range of effects that can occur as a result of a mother consuming alcohol during pregnancy (SAMSHA, 2014). Awareness of the need for professionals to become educated on FASD has emerged as a critical topic in the field of social work and child welfare practice specifically. The social work practice response to children and families, in order to be effective, must develop and emerge from an FASD Informed Practice lens - which implies particular knowledge and competencies in practice. This article will highlight the need to recognize FASD as a disabling condition and identify why training and knowledge is essential in order to work effectively with children and families. Further, an educational pathway to FASD informed practice in relation to a broad array of interventions and enabling/supportive approaches relevant to social work theory will be identified. The focus of this paper is to identifying why knowledge and education on FASD is important to social work practice.
\end{abstract}

Keywords: Fetal Alcohol Spectrum Disorder; social work; disability; curriculum; women's health

1. Associate Professor, Faculty of Social Work, University of Calgary

2. Assistant Professor, Department of Child Studies and Social Work, Mount Royal University

Address for correspondence: badry@ucalgary.ca,pchoate@mtroyal.ca 


\section{Introduction}

We begin this article with a recently published report (2014) regarding the tragic death of a young child in Saskatchewan, Canada in order to critically highlight our strongly held position that the topic of FASD must be included in social work education. This reports reminds us that social work education is the primary career pathway to child protection work in Canada.

This report examines the lives of two young boys we are calling 'Sam' and 'Derek', whose paths crossed tragically on August 21, 2013....The report includes a review of the services both boys received from the Ministry of Social Services (MSS) and the Yorkton Tribal Council Child and Family Services Inc. (the Agency) leading up to Sam's death...Sam was six years old at the time of his death... and was living in a foster home... The RCMP [Royal Canadian Mounted Police] determined that Sam was a victim of homicide, and believes that Derek, age ten at the time was responsible. At the time of the incident Derek was living with his mother and was receiving services... a child under 12 who is suspected of a criminal offence may be considered in need of protection. Derek...was taken into care by the Agency. He remains in their care... The lessons learned here are critical to guiding future case practice for other children with circumstances similar to those of Sam and Derek... Derek was ten years old when he was diagnosed with Fetal Alcohol Syndrome, which is part of Fetal Alcohol Spectrum Disorder (FASD)... Principles of good social work practice were either not known... or simply not practiced...The lack of formal qualifications... and training for staff left them ill-equipped to deliver (required) services... New hires at the Agency may have missed this training or had it delayed...several staff had no CORE training and others had completed only part of the training... In many complex roles and systems, professionals must demonstrate competency in order to practice (physicians, airline pilots, engineers and teachers) and child protection should be no different...Complex stressors and multiple risk factors bring families to the attention of the child protection system. Mental health issues and substance misuse are major contributors... No child deserves to have their life ended as Sam's did. At the same time, no child deserves to have his needs ignored as Derek's were. We have made strong recommendations to improve the casework... (Pringle, 2014)

The voice of Mr. Pringle, offers a sound, rational and objective response after weighing all the evidence in his report Two Tragedies. The portrait on the front page of the report is of two empty swings on a playground, metaphorically representing the loss, grief and systemic failure that contributed to a child's death. 


\section{Narrative review of relevant literature}

A narrative review of the literature was undertaken using the keywords, FASD, social work, human services, curriculum, education, addiction, social welfare, child welfare and training. Using the specific search terms: social work education and FASD, only six potential matches were returned including three journal articles, one report online, and two dissertations. Upon further review it was determined that one doctoral dissertation (Thomas, 2011) was selected as the only key piece of literature relevant to the current inquiry. Thomas' research focused on the literature on alcohol abuse in families, and included social work training and education. She concluded that social workers were the primary profession to work with children affected in their families by alcohol and substance use and, therefore require mandatory training.

In this narrative review we examined prevalence within child welfare, social work education, system responses, social work theories and practice perspectives including person in environment, strengths based, systems, feminist, advocacy, program development, case management and community education.

\section{Prevalence within child welfare}

There are approximately 67,000 children in care in Canada with increasing out of home placements from about 5.7/1000 in 1992 to 9.2/1000 in 2007 (Mulcahy \& Trocmé, 2010. Lange, Shield, Rehm \& Popova, (2013) reported that approximately $6 \%$ (60/1000) of children in child welfare care in Canada had Fetal Alcohol Syndrome (FAS); and 16.9\% (169/1000) had a condition along the spectrum of FASD. True prevalence is difficult to estimate, as FASD is not identified as a reportable health surveillance condition. It is recognized that the real prevalence is likely higher than indicated. Nonetheless, this data emphasizes that social workers will work with affected individuals both within the child protection system as well as other systems that support child welfare.

In our province of Alberta, Canada, almost 10\% or approximately 700 children in care were either diagnosed or suspected to have FASD (Fuchs, Burnside, Long $\&$ Badry, 2014). In cases where FASD is suspected some form of assessment and referral for diagnosis is standard practice. What is unique to Alberta is an FASD Community of Practice that is specifically focused on training caseworkers and foster parents about FASD across all regions in the province. Additionally a model of advanced case consultation, through Workforce Development courses have been offered, beginning in 2013. While individual and team case consultations have been occurring for several years, moving to a model of collaborative training with foster parents, caseworkers and supervisors provides a new learning opportunity and has been well received (Badry, 2013). 


\section{Social work education}

Parton and O'Byrne (2000) suggest that a constructive social work approach, which affirms the importance of dialogue and true listening, is an art more than a science and its basic tenet is that 'we develop a critical stance towards, our taken-for granted ways of understanding the world including ourselves' (p.24). As Parton (2014) notes,

Social work is firmly established in child protection because it is the only profession whose core is based on sociolegal expertise, and continually attempts to mediate across various tensions that inhabit the sphere of 'the social'. (p. 165).

Hacking $(1999,1995)$ suggests that people get diagnosed and are then viewed by their disability rather than their individual personhood. When seen as the diagnosis, the individual capacity is lost. Social work, at its core, is a relationship-based profession. Thus contrary to Hacking's concept, social work should be challenged to see the client as a unique individual whose expression of their FASD will be equally unique. Anecdotally, foster parents, specifically, have largely driven much of the response to FASD in social work practice, and in child welfare. Perhaps we need to extend that conversation. In a study focused on birth mothers who had at least one child who had received an FASD diagnosis through a clinic in Washington state, the seminal work of Astley, Bailey, Talbot \& Clarren (2000a; 2000b) identified 95\% of the 80 women participants as having experienced physical or sexual abuse, almost $60 \%$ living below the poverty line and indicated that over 95\% had mental health problems with 77\% indicating a diagnosis of Post Traumatic Stress Disorder (PTSD). The concerns of birth mothers indicate a population that has had multiple experiences of trauma and it is important to recognize that alcohol is often used to self-medicate.

These are complex families. It is important in social work education to include some preparation to work across the multiplicity of issues represented by FASD including mental health problems, addictions/substance abuse, physical abuse, sexual abuse and historical trauma. The diagnosis of a child with a FASD should represent the need to trace back in a mother's history the roots of the problem. It is this beginning place in which a compassionate response to FASD is found.

\section{System responses}

Glouberman \& Zimmerman (2002) make the point that there is a significant difference between complicated and complex systems. Complicated ones are not simple and indeed have quite intricate components. Yet, they are also highly predictable. The response of the system to specific inputs is such that the outputs can be highly certain, such as flying an airplane or starting the engine of a car. This is not so in complex systems such as health care, child protection and other forms of social work. The inputs are rarely predictable and may often not be known 
beforehand. How people behave defies specific prediction and thus, the output, the person's response to any given stimuli is also quite unpredictable with any degree of certainty. In social work, we can speak of probabilities but not certainties with client behaviors. This is specifically true for individuals living with FASD.

Dupre (2012), in an article on disability and cultural competency in social work practice highlighted that social work literature has a dearth of studies related to disability. Further, she suggests that social work while strongly oriented to responding to oppression, as a profession, maintains limited awareness of disability culture. Many children with FASD have lived with significant oppression arising from the diagnosis as well as the family dysfunction that they have endured such as the chaos of parental addiction (Boris, 2009)

It is well established that there are a number of impacts from the FASD in areas of decision-making, self-regulation and problem solving (Andrew, 2011; Green et al., 2009). The degree of disruption will vary greatly depending where upon the spectrum any given client might be. As well, given that the brain can be quite variously impacted depending upon such factors as when in the pregnancy the fetus was exposed or how much and how often the mother drank, each case is highly unique. Paley \& O'Connor (2011) have described specific behavioral challenges for individuals with an FASD diagnosis including challenges with self-regulation, poor social skills and executive functioning which impacts decision-making. While these have been framed by Streissguth (1997) as secondary disabilities, they appear to be more representative of social problems that are a result of FASD as a primary disability. Mental health issues are also a co-morbid concern. Preparing students to work in the field therefore requires that their case management skills be tempered to manage this uncertainty.

One of the greatest challenges to the social work profession is recognizing that FASD is frequently an 'invisible disability'. The social/behavioral profile of an individual provides the greatest clue to consider FASD as a potential cause for dysfunction. This is particularly true for individuals who present with strong verbal skills and have no visible signs of a disabling condition. Individuals who live with undiagnosed and unrecognized FASD will struggle their whole life. A formally assessed diagnostic conclusion allows individuals the right interventions while also separating out those who are impacted by other disabilities requiring different therapeutic approaches.

Children, particularly when removed from parental care, face placement breakdown if not understood. As youth, the needs for consistency, structure and routine are increasingly critical due to their vulnerability to peer influences and engagement in risky behaviors (Williams, 2006). In late adolescence and early adulthood issues such as becoming parents can lead to child protection intervention. Again, drawing upon Hacking (1999; 1995), parents who have FASD face the risk of being automatically presumed to be incapable of parenting or having a significant role in the raising of their children (Choate, 2013). 
However, our stance would be that the social work profession has a responsibility to educate students on FASD due to the gamut of social/behavioral problems. In a survey by Caley (2008) of over 1150 human service professionals in the United States including foster parents, it was reported that over $70 \%$ pf the participants did not feel prepared to care for or manage cases where children had FASD. While over 40\% of participants had taken some training on FAS and the effects of alcohol exposure, over $80 \%$ indicated that they had no training and knowledge about interventions, making referrals and assisting clients. Caley et al., (2008) recommended the need for training on screening, interventions and support particularly in relation to the social/behavioral challenges faced by children with FASD.

As a result of the above noted problems, social workers will also need to manage a higher degree of uncertainty than exists with others due to poor retention skills of many clients with FASD. This is again impacted by where the client might be on the spectrum. Yet, even for those with what may be considered mild effects of FASD, there remain quite profound challenges in very specific areas of functioning as a result of the particular brain function impacted by the disorder.

Certain areas of practice have been found to have a higher prevalence of clients with or suspected of having FASD. These include child protection, criminal justice, disabilities and mental health (Fuchs, et al., 2010; Williams, 2006.) There is also a high frequency of co-existing disorders bringing clients into multiple systems simultaneously. These include Attention Deficit Hyperactivity Disorder, anxiety disorders, Oppositional Defiant Disorder, adjustment disorders, Conduct Disorder, and depression (Bertrand, Floyd \& Weber, 2005). These require complex case management social work skills (Badry, 2013, 2009). It is for these reasons that we suggest that a multitude of social work theories and practices should be taught, but done so from an FASD lens. Clients, who must find ways to function within a complex world, are unlikely to do so successfully without informed support systems.

\section{Social work theory}

While schools of social work present students with theories in a broad sense, FASD is a pervasive disorder that is found in most clinical settings. It, and its comorbid disorders, make it one of the most common issues but also an issue that receives less attention than other mental health, behavioral or relational issues. We argue that the student should receive specific education that blends major social work theories and perspectives with the specific concerns of FASD.

\section{Person in Environment (Hare, 2004)}

The essential element of this approach is the interconnected relationship that a client has with the environment in which they live and function. By mapping this, social workers are able to explore the naturalistic supports as well as the risks that 
a client may have. Since FASD is typically associated with at least one member of the family abusing substances, this means that the environment may be chaotic leading to involvement of health, justice and child protection workers. By utilizing this approach with clients who have FASD, a social worker is also able to assess the client's perception of these influences on their life. This opens up a conversation regarding how a client may view risk including their level of insight and coping mechanisms.

\section{Strengths' Perspective (Saleebey, 1996)}

Long a tenant of social work, the strengths' perspective is of vital importance in working with clients living with FASD. Clients brought to the attention of a social service system will have challenges leading to a deficit perspective. Progress with such a client is in changing their perspective through discovering strength and experiencing their environments differently. While such an approach does not deny the deficits, it seeks to maximize strengths while working with a support system to balance deficits. This approach has been successful in many other disability communities increasing meaningful participation (Hammel et al., 2008). The strengths perspective considers how clients function within the community and the family system allowing for meaningful roles (Choate, 2013).

Munro (2011) has made a compelling case that child protection work should be relationship based not only with the client but also across the various systems that support the client. It is from this perspective that the strengths of the client and the naturalistic and formal supports can be considered allowing the growth of potential.

\section{Systems Theory (Forder, 1976)}

As the prior two points suggest, progress will be made through understanding the environments in which the client functions, but is further enhanced by also considering a systemic view, particularly focusing upon either the family system in which the client lives or the other interpersonal systems that make up the client's day to day connections. Within these systems will be supports but also elements which constitute risk. The systemic approach helps the social worker to consider how these supports can be strengthened but also what needs to be replaced as risk connections are weakened. Social work students can use the systems approach to think about how a change in one aspect of the system (such as a risk factor) will ripple throughout the system. This will link directly to case management.

A systems approach also opens up an understanding of intergenerational impacts that exist within the client's world. The majority of those diagnosed with FASD come from family systems where addiction, mental health, abuse and trauma lie within the family story. In Canada, for example, within the First Nations communities, there has been a history of state imposed trauma that includes forced family separations into residential schools that we now understand were rife with various forms of abuse and maltreatment. This was compounded with what has become known as 
the 'Sixties Scoop' where large numbers of Aboriginal children were apprehended. This has led to an increase in trauma related outcomes in many parts of the First Nations communities, including high levels of substance abuse (RCAP, 1996). It is vital that such communal trauma histories be understood when working with clients, their families and community support services (Menzies, 2007). There are many good examples of how such intergenerational traumas can be addressed through a systems approach (an example is Quinn, 2007). Drawing on Community Social Work to build programs that are rooted in community needs, these traumas can also be addressed from a programming perspective.

\section{Case management}

This skill may often be missed as part of the social work training in this area of practice but it is one that brings together assessment and action, recognizing that no one professional likely holds the supports needed for a client with FASD. Collaborative planning crosses disciplines while not leaving the client impacted by FASD to determine how they are to find their way between services. Even moderately affected clients can easily be overwhelmed by the demands of meeting various professionals, in various locations with a variety of appointment schedules.

Case planning permits priority setting so that the load of obligations can be kept within the tolerance levels of the client. Without case management, clients are set up for failure as service system management is a sophisticated skill set that most clients with FASD do not possess (Badry, 2009). Case management is also a place for social work to regain its voice in the interdisciplinary world of specialty services. Medical assessments, psychiatric management, judicial connections, financial support systems and community services require solid information in order to better serve the client. Advocacy, an approach strongly connected to social work, is needed for this client population who are too easily overwhelmed to successfully self-advocate in many situations. Social work must be at the table with other professions but must do so in a lead role given the professions unique view across the client's environments. Too long has social work failed in this regard ceding position to professionals with hierarchical position but it is often done at the expense of this client group who struggle to coordinate their message. This leads to interdisciplinary practice. Social work educators should intentionally build these skills. It is often not at the forefront of social work training as much effort is made in building knowledge of the theories and practice perspectives. By creating cross discipline training we also enhance the value of social work within the other professions as they become exposed early on in their career to what the profession can do.

\section{Advocacy}

Clients with disabilities face quite a number of barriers ranging from how they are perceived as a human being through to whether services exist to support clients in ways that improve their lives. In responding to FASD, there is a unique dynamic 
of clients that are often characterized as highly damaged individuals who are the product of negligent mothers bearing children with dismal prospects. Clients need advocacy at the personal level with a variety of services but also at a social policy level. The image of FASD needs challenging such that policy makers and service providers begin to see the spectrum in the disorder (Choate, 2014). Through advocacy there is an opportunity to begin to no longer think of it as a homogeneous disorder but one where individual expressions vary widely across the spectrum. While the FASD cannot be undone, much of the impact of environment, effects of stress in the pregnancy, social skills and decision making can be successfully impacted. Yet those who build programs may fail to recognize the possibilities.

Advocacy is an opportunity to bring in a Feminist perspective given that the vast majority of mothers who have children with FASD are themselves members of marginalized and traumatized populations (Marcellus, 2007). Those abusing substances have histories of trauma related to various forms of abuse. Many of these mothers have not sought pregnancy and thus, in the middle of active addictions, find themselves in a position of further vulnerability caught between the pregnancy and the addiction. The mothers are typically quite aware that child protection lingers on the horizon following the birth. Advocacy for treatment and support services as the mother starts to come to grips with being pregnant can begin a different life course for both herself and the baby (Weaver, 2007). The window is also then open for an Anti-Oppressive view in which the mother can be seen as much as a victim of her history, a person in need of treatment and not as an abuser who is inflicting harm upon her unborn child.

\section{Program development}

Taking the above skills and practice approaches into direct work with clients requires that programs also operate with an FASD sensitive lens. Clients require longer agency involvement, from months to years, in order to achieve stability. Helping students learn program development, leadership and management skills will build competency in this crucial area of service delivery.

\section{Community education}

Part of the role in changing the FASD landscape is altering how the community understands and responds to FASD. The social educational role ensures that social workers are part of that conversation. Rather than a purely psychological or medical perspective, social work can begin connecting with various populations about the ways in which those with FASD can be cherished, strengthened and included. This becomes a way to change the conversation around FASD from the present sense of certain failure to one of possibilities. One author (DEB) has participated in the development of a website for care givers, social workers and others working with FASD within the child protection system (http://www.fasdchildwelfare.ca - Badry $\&$ Hickey, 2014). The goal is to provide balanced and valid information. 


\section{Discussion}

FASD is one of the more complex issues facing social workers today. It transcends a variety of environments including child protection, schools, health care, criminal and family courts, police, probation and mental health services, increasingly through the life span as more people are diagnosed at different stages of life. The social work voice is needed across these systems. Needs may be moderate to high with supports required over many years. It is virtually impossible for social workers in most high needs service areas to not work with clients with FASD.

Given its complexity, FASD acts as a highly powerful issue to focus social work education around. It is an issue that requires social workers to draw from many theoretical and interdisciplinary practice perspectives. When recognized as a lifelong disability, the challenge of providing routine, structure and support over a lifetime is daunting.

We expect social work students to learn to manage and respond to multiple case needs. They must be able to work across systems and professions taking a lead position as both case managers and agents of service delivery. Addressing FASD needs means that students develop an enhanced understanding of what it means to practice.

The FASD community is also in urgent need of what social work can offer. Too often the dialogue focuses upon epidemiological, diagnostic and behavioral containment strategies. Social work can begin to change the conversation by shifting it towards what is possible for clients and bringing in tools that have been shown create a difference where disability is a concern for a client.

\section{Conclusions: Social work education as a critical tool for change}

Concerns in supporting an individual with FASD are many. Social work education must include a pathway to FASD informed practice in relation to a broad array of interventions and enabling/supportive approaches. In children and families, where FASD is a concern, there is increased risk for contact with the child welfare system and children are often placed in care. Lange, et al., (2013) estimated that approximately $22 \%$ of children in care in Canada have either Fetal Alcohol Syndrome (FAS) or FASD.

Through training and education the perception of those caring for the child shifts and changes. The knowledge and value of perceiving FASD as a disability due to the neurological challenges associated with brain damage and other impacts of prenatal alcohol exposure can change practice. Children with FASD require understanding and in the Alberta experience, offering such training represents a critical effort in improving the lives of children in care with FASD. This training shifts an understanding of the child and highlights the need to see the child 'as hurt 
- not bad'(D. Debolt, personal communication, 2013) and to adapt the environment based on the needs of the child. It is those around the child that need to adjust and make changes, as the child may not have the capacity to do so. It is vital that professional caseworkers and foster parents receive training in order to effectively respond to children with FASD and their families.

The capacity of a caregiver to provide for, and meet the needs of the child is predicated on an understanding of the unique and distinct needs of the child.

Given the nature of the disorder, FASD will impact clients throughout the life span. There remain many gaps in the research, not just in child protection but also the impact of FASD at various stages of life. Given the strong clinical connection between social work and FASD, social work should position itself to provide leadership and excellence in research and practice.

\section{References}

Andrew, G. (2011) Diagnosis of FASD: An overview. in, E.P. Riley, S. Clarren, J. Weinberg and E. Jonsson (Eds) Fetal Alcohol Spectrum Disorder: Management and policy perspectives. (pp.127-148) Weinham, Germany: Wiley-VCH Verlag

Astley, S., Bailey, D. Talbot, C. and Clarren, S.K. (2000a) Fetal Alcohol Syndrome (FAS) primary prevention through FAS diagnosis: I. Identification of high-risk birth mothers through the diagnosis of their children. Alcohol \& Alcoholism, 35, 5, 499-508

Astley S., Bailey D., Talbot C., Clarren S.K.(2000b) Fetal alcohol syndrome (FAS) primary prevention through FAS diagnosis: II. A comprehensive profile of 80 birth mothers of children with FAS. Alcohol \& Alcoholism, 35, 5, 509-519

Badry, D. (2013) The FASD (Fetal Alcohol Spectrum Disorder) Community of Practice (CoP) in Alberta Human Services: Leading from Within Initiative. Alberta Centre for Child, Family and Community Research

Badry, D. (2009) Fetal Alcohol Spectrum Disorder Standards: Supporting children in the care of children's services. First Peoples Child \& Family Review, 4, 1, 47-56

Badry, D. and Hickey, J. (2014) The Caregiver Curriculum on FASD. Alberta: Canada. Online: www.FASDchildwelfare.ca

Bertrand, J., Floyd, R.L. and Webber, M.K. (2005). Guidelines for identifying and referring persons with Fetal Alcohol Syndrome. MMR Weekly 54 (RR11), 1-10

Boris, N.W. (2009) Parental substance abuse. in, C.H. Zeanah (Ed.) Handbook of Infant Mental Health (3d ed.). (pp. 171-179) New York: Guilford

Caley, L., Syms, C., Robinson, L., Cederbaum, J., Henry, M., and Shipkey, N. (2008) What human service professionals know and want to know about fetal alcohol syndrome. Canadian Journal of Clinical Pharmacology, 15, 1, el17-e123

Choate, P. (2014, October) Public policy and Fetal Alcohol Spectrum Disorder: The need to change the conversation. Keynote presentation to the Alberta FASD Conference, Edmonton, AB 
Choate, P. (2013) Parents with Fetal Alcohol Spectrum Disorders in the child protection systems: Issues for parenting capacity assessments. First Peoples Child and Family Review, $8,1,81-92$

Dupre, M. (2012) Disability culture and cultural competency in social work. Social Work Education: The International Journey, 31, 2, 168-183. http://doi.org/10.1080/02615479.2 012.644945

Forder, A. (1976) Social work and system theory. British Journal of Social Work, 6, 1, 23-42

Fuchs, D., Burnside, L., Marchenski, S., and Mudry, A. (2010) Children with FASD related disabilities receiving services from child welfare in Manitoba. International Journal of Mental Health and Addiction, 8, 232-244. http://doi.org/10.1007/s11469-009-9258-5

Fuchs, D., Burnside, L., Long, D., and Badry, D (2014, October) FASD counts! The challenges of estimating the numbers of children and youth affected with FASD: Results of a Tri-provincial study. Presented at Prairie Child Welfare Consortium Symposium, Saskatoon, SK

Glouberman, S. and Zimmerman, B. (2002) Complicated and Complex Systems: What would successful reform of Medicare look like? Discussion Paper 8. Ottawa, ON: Commission on the Future of Health Care in Canada

Green, C.R., Mhic, A.M., Nikkel, S.M., Stade, B.C., Rasmussen, C., Munoz, D.P. and Reynolds, J.N. (2009) Executive function deficits in children with fetal alcohol spectrum disorder (FASD) measured using the Cambridge Neuropsychological Test Automated Battery (CANTAB). Journal of Child Psychology and Psychiatry, 50, 6, 683-697. http://doi. org/10.1111/j.1469-7610.2008.01990.x

Hacking, I. (1999) The Social Construction of What? Cambridge, MA: Harvard University Press Hacking, I. (1995) The Looping Effects of Human Kinds. in, D. Sperber and A.J. Premack (Eds.), Causal Cognition. (pp.351-383) Oxford: Oxford University Press

Hammel, J., Magasi, S., Heinemann, A., Whitemeck, G., Bogner, J., and Rodriguez, E. (2008) What does participation mean? An insider perspective from people with disabilities. Disability and Rehabilitation, 30, 9, 1445-1460. http://doi.org/ doi:10.1080/09638280701625534

Hare, I. (2004) Defining social work for the 21st century. The International Federation of Social Workers 'revised definition of social work. International Social Work, 47, 407-424. http://doi.org/10.1177/0020872804043973

Lange, S., Shield, K., Rehm, J., and Popova, S. (2013) Prevalence of Fetal Alcohol Spectrum Disorders in child care settings: A meta-analysis. Pediatrics, 132, 4, e980-e995

Marcellus, L. (2007) Using feminist ethics to inform practice with pregnant women who use substances. in, S.C. Boyd and L. Marcellus (Eds.) With child: Substance use during pregnancy: A woman-centered approach. pp. 28-36. Black Point, NS: Fernwood Publishing Menzies, P. (2007) 'Understanding Aboriginal intergenerational trauma from a social work perspective.' The Canadian Journal of Native Studies, 27, 2, 367-392

Mulcahy, M., and Trocme, N. (2010) Children and youth in out-of-home care in Canada: Centre of Excellence for Child Welfare (CECW) information sheet \#78. Montreal, QC: Centre for Research on Children and Families, McGill University

Munro, E. (2011) The Munro Review of Child Protection: Final Report. London: Department of Education 
Paley, B. and O'Connor, M. (2011) Behavioral interventions for children and adolescents with Fetal Alcohol Spectrum Disorder. Alcohol Research and Health, 34, 1, 64-75

Parton, N. (2014) The politics of child protection: Contemporary developments and future directions. Hampshire, UK: Palgrave Macmillan

Parton, N. and O'Byrne, P. (2000) Constructive Social Work: Towards a New Practice. London: Palgrave Macmillan

Pringle, B. (2014) Two Tragedies: Holding Systems Accountable, Special Investigation Report. Saskatoon, SK: Saskatchewan Youth Advocate

Quinn, A. (2007) Reflections on Intergenerational Trauma: Healing as a Critical Intervention. First Peoples Child and Family Review, 3, 4, 72-82

Rasmussen, C., Wyper, K., and Talwar, V. (2009) The relation between theory of mind and executive functions in children with fetal alcohol spectrum disorders. Canadian Journal of Clinical Pharmacology, 16, 2, e370-e380

Royal Commission on Aboriginal Peoples (1996) Report of the Royal Commission on Aboriginal Peoples. Ottawa: Royal Commission on Aboriginal Peoples

Saleebey, D. (1996) The strengths perspective in social work practice: Extensions and cautions. Social Work, 41, 3, 296 -305. http://doi.org/10.1093/sw/41.3.296

Streissguth A. (1997) Fetal alcohol syndrome: a guide for families and communities. Baltimore, MD: Paul H. Brooks

Substance Abuse and Mental Health Administration (2014) Addressing Fetal Alcohol Spectrum Disorder (FASD) Treatment Improvement Protocol (TIP) Series 58. Rockville, MD: Substance Abuse and Mental Health Administration

Thomas, M.M. (2011) A Content Analysis of Literature on Alcohol Abuse in Families, Including Social Workers' Training and education in this Area. Unpublished Master of Social Work Thesis at the California State University, Long Beach

Weaver, S. (2007) 'Make it more welcome': Best practice child welfare work with substance using mothers - diminishing risks by promoting strengths. in, S.C. Boyd and L. Marcellus (Eds.) With Child: Substance use during pregnancy: A woman-centered approach. (pp. 76-90) Black Point, NS: Fernwood

Williams, S.J. (2006) Research brief: Is there justice in the juvenile justice system- Examining the role of Fetal Alcohol Spectrum Disorder. Justice Policy Journal, 3, 1-15

Wilson, A. (2013) A social work student's developing understanding of Fetal Alcohol Spectrum Disorder from medical and social perspectives and implications for practice. First Peoples Child E Family Review. 8, 1, 25-39 